\title{
PHẪU THUẬT CÃ́T U NHẦY NHĨ PHẢI THÔNG BÁO BA TRƯờnG HợP
}

Phùng Duy Hồng Sơn*, Nguyễn Hũu Uớc *, Đoàn Quốc Hưng*, Vũ Ngoc Tú*

\section{TÓM TẮT}

Thông báo lâm sàng 03 trường hợp $\mathrm{u}$ nhầy nhĩ phải được phẫu thuật thành công ở tại khoa Phẫu thuật Tim mạch và Lồng ngực, bệnh viện Hữu nghị Việt Đức, giai đoạn 2016 - 2017. Chẩn đoán xác định u nhầy nhĩ phải ở ca thứ 1 và 2 không quá khó khăn do u không lớn - di động mạnh - cuống u rõ, nhưng với ca 3 thì đã phải làm nhiều thăm dò loại trừ ung thư thứ phát do u quá to và vôi hóa bên trong. Phẫu thuật $\mathrm{ca} 1$ bằng mổ tim hở kinh điển qua đường dọc giữa xương ức + canuyn tĩnh mạch chủ dưới qua tĩnh mạch chậu - do u nằm thấp sát lỗ tĩnh mạch chủ dưới; ca 2 bằng phẫu thuật tim ít xâm lấn có nội soi hỗ trợ qua đường mở ngực nhỏ; ca 3 bằng mổ tim hở kinh điển rộng rãi để thăm dò và xử lý khối u chiếm gần toàn bộ lòng nhĩ phải. Diễn biến hậu phẫu đề thuận lợi. Kết quả kiểm tra sau mổ tốt. Tù khóa: u nhầy, nhĩ phải, Việt Đức, phẫu thuật tim hở, ít xâm lấn.

\section{SUMMARY}

Clinical report 03 cases of myxoma must be successfully operated at the Center of Cardiovascular and Thoracic Surgery, Viet Duc University Hospital, from 2016 to 2017. Results: The diagnosis of right atrial myxoma at first and second cases ware not too difficult because the tumor was not large - strongly moving - the tumor's roots ware clear, but in third case had to do many probes to exclude secondary cancer due to big size and calcified inside of tumor. Open heart surgery was done for all 3 cases: through median sternotomy with inferior vena cava cannula by iliac vein introducer because the tumor is located close to the hole of inferior vena cava - for the first case; with minimally invasive cardiac surgery through a small open right chest - for second case; through classical median sternotomy to explore and treat a big myxoma occupying the entire right atrium - for third case. Postoperative progress is favorable. Good postoperative results.

Key words: myxoma, right atrium, Viet Duc, open heart surgery, minimally invasive cardiac surgery.

\section{I. ĐẶT VẤN ĐỀ}

U tại tim chỉ chiếm khoảng $0,2 \%$ tất cả các loại u của cơ thể. Các khối u này có thể là nguyên phát, thứ phát hoặc di căn [4]. Tỷ lệ u thứ phát hoặc di căn nhiều gấp 20 - 40 lần u nguyên phát. Do vậy, rất hiếm gặp u nguyên phát ở tim [5-7].

U nhầy (Myxoma) là u nguyên phát thường gặp nhất ở tim $(\approx 50 \%)$. U nhầy là loại u lành tính, tuy vậy những hậu quả gây ra do cản trở huyết động học và biến chứng do rụng-vỡ các mảnh u thường rất nặng. Do vậy u nhầy tim, nếu phát hiện cần phải điều trị ngay, hạn chế biển chứng gây tử vong hoặc để lại di chứng nặng nề. U nhầy phát triển từ các tế bào trung mô của lớp nội tâm mạc [8]. Vị trí u nhầy ở nhĩ trái chiếm $80-85 \%$, biểu hiện lâm sàng tương tự triệu chứng của hẹp van hai lá và/hoặc biến chứng do tắc mạch cấp tính. Vị trí u nhầy ở nhĩ phải chỉ chiếm 15-20\% [2-7]. Do vậy, rất ít báo cáo trong nước đề cập đến chủ đề này. Với mục đích giới thiệu kinh nghiệm chẩn đoán và điều trị một nhóm bệnh tim mắc phải hiếm gặp, báo cáo sẽ trình bày 3 ca lâm sàng u nhầy nhĩ phải được phẫu thuật thành công tại Trung tâm phẫu thuật tim mạch và lồng ngực, Bệnh viện

\footnotetext{
*Trung tâm Phẫu thuật Tim mạch và Lồng ngưc, bệnh viện Hũu nghị Việt Đức, Bộ môn Ngoại, Đại học Y Hà Nội Ngưòi chịu trách nhiệm khoa học: PGS.TS. Đoàn Quốc Hung Ngày nhận bài: 01/04/2018 - Ngày Cho Phép Đăng: 10/04/2018 Phản Biện Khoa học: PGS.TS. Đặng Ngọc Hùng
} GS.TS. Lê Ngọc Thành 
Hữu nghị Việt Đức trong hai năm 2016-2017.

\section{TRÌNH BÀY CÁC CA LÂM SÀNG}

\subsection{Ca lâm sàng thứ 1}

Bệnh nhân nữ - 31 tuổi, dân tộc Dao, xuất hiện khó thở theo cơn và khi thay đổi tư thế nghiêng trái trước vào viện 3 tháng, hơn 1 tháng nay bị ho nhiều. Bệnh viện tỉnh khám chẩn đoán u tim, nên chuyển đến bệnh viện Việt Đức xét phẫu thuật cắt $\mathrm{u}$. Lâm sàng khi vào viện không có dấu hiệu thần kinh khu trú, không có biểu hiện nhiễm trùng, khó thở khi nằm nghiêng trái - đầu cao, NYHA II, tim đều, gan $2 \mathrm{~cm}$ dưới bờ sườn phải, chân không phù.

Trên siêu âm tim: chức năng tim trong giới hạn bình thường, các van tim không hẹp hở, trong buồng nhĩ phải có khối đậm âm, kích thước $25 \times 38 \mathrm{~mm}$, cuống nhỏ bám vào vách liên nhĩ, di động nhiều, thì tâm trương di động vào buồng thất phải, qua van ba lá, gây hẹp van ba lá. Khi di chuyển, u nằm sát lỗ đổ về của tĩnh mach chủ dưới.

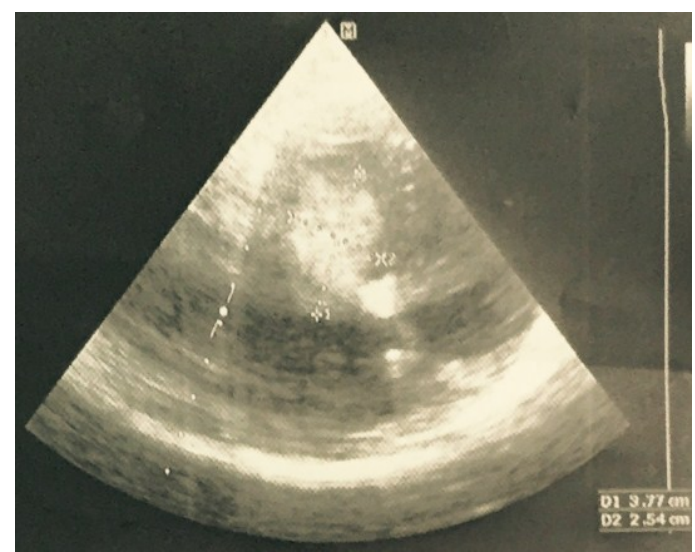

Hinh 2.1: Hình u nhầy nhĩ phải trên siêu âm

Trên MSCT: có vùng khuyết cản quang trong nhĩ phải, ranh giới rõ, không xâm lấn các tổ chức xung quanh. Động mạch phổi hai bên không có thuyên tắc. Không có u trung thất và u phổi.

Chẩn đoán xác định là U nhầy nhĩ phải được chỉ định phẫu thuật tim hở cắt bỏ u.

Kỹ thuật mổ: mở đường giữa xương ức, canuyn động mạch chủ và tĩnh mạch chủ trên; riêng tĩnh mạch chủ dưới được canuyn qua da từ tĩnh mạch chậu trái theo kỹ thuật Seldinger. Kiểm soát tĩnh mạch chủ trên bằng đặt lắc thường qui. Kiểm soát tĩnh mạch chủ dưới bằng kẹp mạch máu to. Tuần hoàn ngoài cơ thể toàn bộ lưu lượng, không ngừng tim. Mở nhĩ phải thấy khối u 20 x 30mm - bám vào vách liên nhĩ bằng một cuống nhỏ, cách vòng van ba lá $10 \mathrm{~mm}$, sát tĩnh mạch chủ dưới. Đặt 1 ống hút hút máu trở về - làm khô lỗ xoang tĩnh mạch vành, luồn kẹp phẫu tích cặp chân khối u, cắt $u$ bằng dao mổ - gửi giải phầu bệnh. Đốt kỹ diện bám u bằng dao điện, khâu tăng cường chân $\mathrm{u}$ bằng chỉ prolen 5.0. Van ba lá thanh mảnh - hở do giãn vòng van, được sửa van theo kỹ thuật De Vega. Đóng nhĩ phải, ngừng tuần hoàn ngoài cơ thể.

Bệnh nhân rút ống sau mổ 2 giờ, xuất viện sau 7 ngày. Kết quả giải phẫu bệnh làu nhầy.

\subsection{Ca lâm sàng thứ 2}

Bệnh nhân nữ - 63 tuổi, vào Việt Đức để mổ u góc cầu tiểu não; trong khi làm bilan trước mổ, phát hiện khối u nhĩ phải đường kính $15 \times 25 \mathrm{~mm}$ trên siêu âm tim, cuống bám ở vách liên nhĩ, di động nhiều nhưng không lọt vào lỗ van ba lá. Trên MS-CT không thấy thuyên tắc động mạch phổi, không có u trung thất hay $\mathrm{u}$ phổi. Hội chẩn liên khoa xác định hai khối u có nguồn gốc độc lập, u góc cầu tiểu não tiên lượng tốt - có thể để mồ sau, $u$ ở tim là $u$ nhầy nhĩ phải, cần điều trị trước.

Kỹ thuật mổ: phẫu thuật tim hở ít xâm lấn có nội soi hồ trợ qua đường mở ngực phải nhỏ $4 \mathrm{~cm}$ (minimally invasive cardiac surgery MICS). Thiết lập tuần hoàn ngoài cơ thể qua canuyn động tĩnh mạch đùi và tĩnh mạch chủ trên qua đường cổ. Chạy tuần hoàn ngoài cơ thể toàn bộ lưu lượng - không ngừng tim. Mở nhĩ phải, cắt $\mathrm{u}$ - khoét toàn bộ cuống $\mathrm{u}$, khâu trực tiếp lỗ thủng chân u ở vách liên nhĩ.

Bệnh nhân được rút nội khí quản sau mổ 1 giờ, chuyển điều trị u não sau 7 ngày.

\subsection{Ca lâm sàng thứ 3}

Bệnh nhân nữ - 56 tuổi, nhập viện do mệt mỏi và khó thở xuất hiện từ trước đó 3 tháng. 
Khám lâm sàng thấy thể trạng trung bình (cao $154 \mathrm{~cm}$, nặng $47 \mathrm{~kg}$ ), NYHA II, không có biểu hiện nhiễm trùng.

Các thăm dò cận lâm sàng:

Xquang tim phổi thẳng thấy bóng tim to, giãn nhĩ phải (H.1).

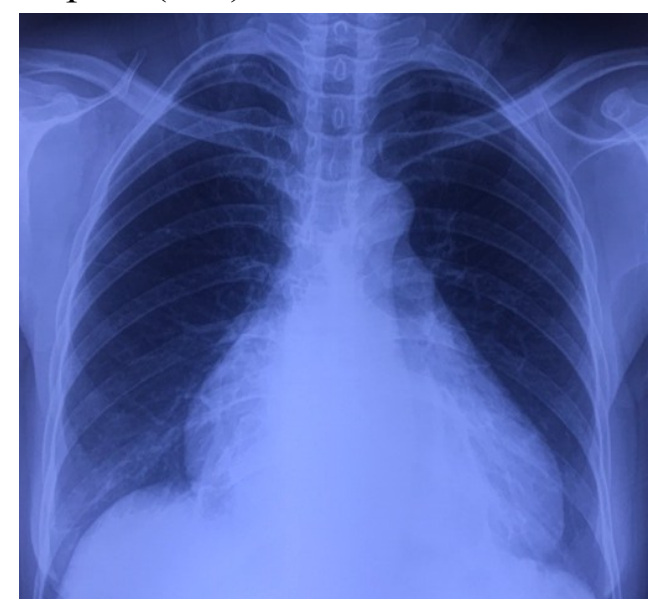

Hinh 2.2. Xquang phổi thẳng

Siêu âm tim thấy khối u lớn trong nhĩ phải kích thước $64 \mathrm{x} 44 \mathrm{~mm}$, bờ không đều, chân bám vào $1 / 3$ trên vách liên nhĩ, di động nhiều gây hẹp vừa van 3 lá (H.2).

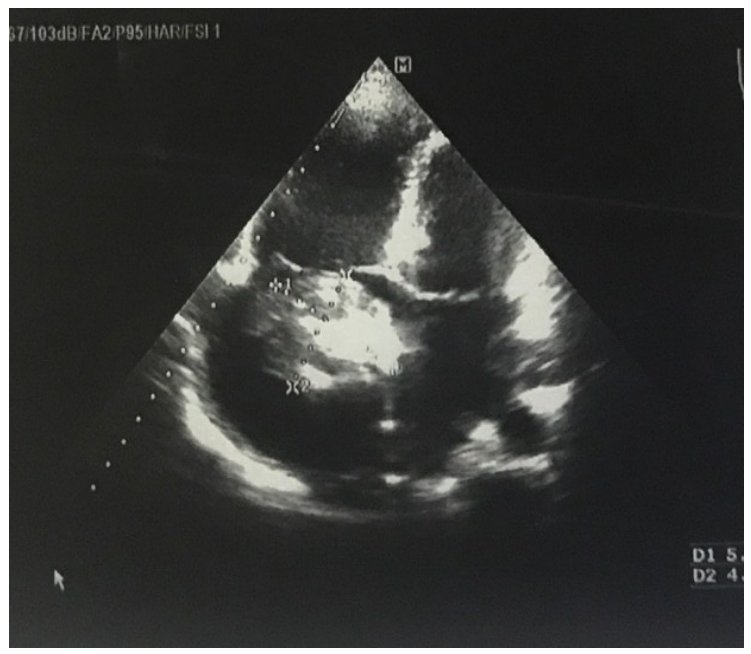

Hình 2.3. Siêu âm tim

Có vôi hoá trong $\mathrm{u}$, van hai lá hở 1,5/4, phân suất tống máu thất trái (EF) $73 \%$.

Cắt lớp vi tính 64 dãy thấy nhĩ phải to, khối u nhĩ phải kích thước $68 \times 47 \mathrm{~mm}$ giảm tỷ trọng, không ngấm thuốc cản quang, bên trong có vôi hoá, ranh giới rõ (H.3). Không có u trung thất lân cận, u phồi.

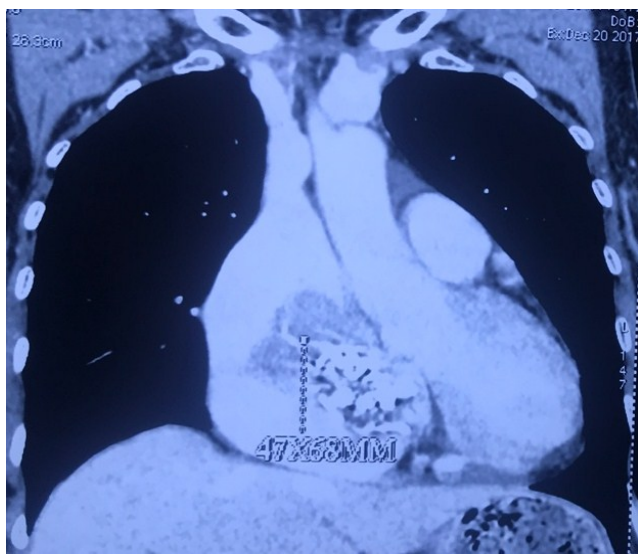

Hinh 2.4. Chup cắt lớp vi tính 64 dãy

Thăm dò toàn thân không phát hiện ra u ở cơ quan khác (bụng, tiết niệu, não).

Chẩn đoán xác định: khả năng cao là $\mathrm{u}$ lành tính nhĩ phải (u nhầy), có thể cắt bỏ, nên đã chỉ định phẫu thuật.

Kỹ thuật mổ: phẫu thuật tim hở kinh điển qua đường giữa xương ức. Cặp động mạch chủ và liệt tim bằng máu ấm. Nhĩ phải giãn lớn. Mở nhĩ phải thấy khối u kích thước 70x50mm, ranh giới rõ, mặt nhẵn, chân bám diện rộng vào vách liên nhĩ (H.4-5).



Hình 2.5. Khối u chiếm phần lớn nhĩ phải

Cắt triệt để khối u và chân bám - gây khuyết vách liên nhĩ lớn. Vá phục hồi vách liên nhĩ bằng miếng vá nhân tạo; sửa van ba lá theo kỹ thuật De Vega. Kết quả giải phẫu bệnh tức thì và sau mổ đều trả lời là u nhày nhĩ.

Bệnh nhân được rút ống nội khí quản 12 giờ sau mổ. Kiểm tra sau mổ tốt. Ra viện vào ngày thứ 10. 


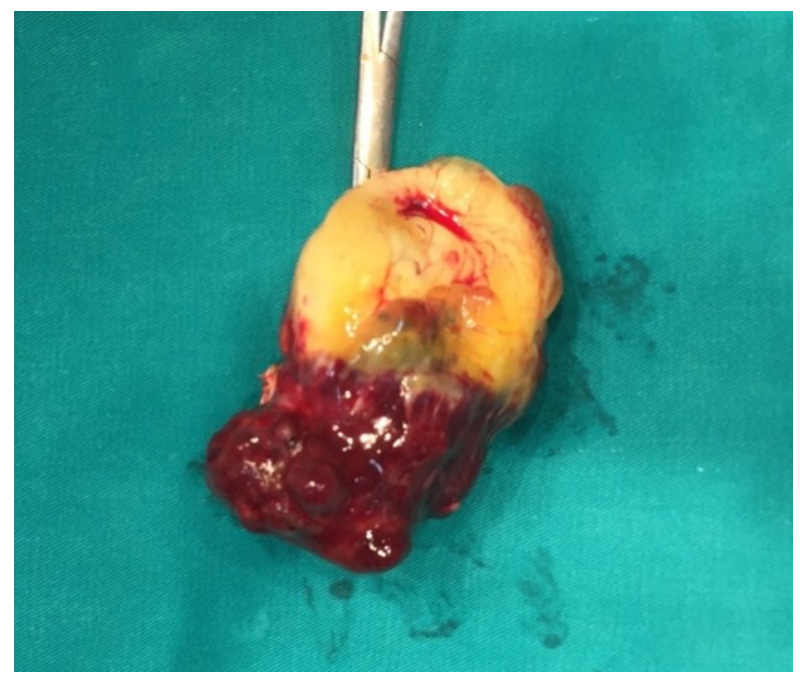

Hình 2.6. U sau khi cắt bỏ

\section{BÀN LUẬN}

U nhày nhĩ phải gặp trong $15-20 \%$ u nhày của tim; tỷ lệ nữ giới chiếm $70 \%$ và thường gặp ở độ tuổi từ 30-60 tuổi. Triệu chứng lâm sàng phong phú và không đặc hiệu, có thể gặp sốt, gầy sút cân, khó thở, hội chứng Raynaud, thiếu máu, tăng gammaglobulin, đau khớp. Tuy nhiên, biểu hiện khó thở và suy tim phải là hay gặp hơn cả [6-9]. Triệu chứng lâm sàng phụ thuộc vào vị trí, kích thước, khả năng di động của khối $u$ và thường mất đi sau khi khối $u$ được cắt bỏ [10]. Vị trí cuống u nhày nhĩ phải hay gặp là tại vách liên nhĩ và cạnh lỗ bầu dục. U lớn sẽ gây các cản trở dòng chảy về nhĩ phải, các thương tổn cấu trúc van ba lá hoặc ảnh hưởng tới dòng chảy qua van [11]. Do không có biểu hiện lâm sàng đặc hiệu nên trước đây $\mathrm{u}$ nhày nhĩ chỉ được phát hiện thông qua giải phẫu tử thi. Ngày nay, chẩn đoán $u$ nhày nhĩ tương đối đơn giản qua siêu âm tim; nhưng những khối u nhỏ dưới $5 \mathrm{~mm}$ cần phải được siêu âm qua thực quản để xác định một cách chính xác hơn [11]. Trong nghiên cứu của chúng tôi cả 3 trường hợp lâm sàng đều là nữ, với triệu chứng chung là khó thở và mệt mỏi, sút cân; riêng trường hợp thứ 2 không có biểu hiện lâm sàng. Trên siêu âm tim thấy khối nhĩ phải xuất phát từ vách liên nhĩ, di dộng tốt gây hẹp vừa van ba lá ở thì tâm trương. Chỉ định chụp cắt lớp vi tính đa dãy có cản quang được đặt ra cho tất các trường hợp có khối nhĩ phải nhằm loại trừ $\mathrm{u}$ trung thất, $\mathrm{u}$ phổi xâm lấm tim phải, điều mà trong thực hành lâm sàng đều đã gặp, ngoài ra còn cho phép đánh giá hệ động mạch phổi. Nếu trong trường hợp có thuyên tắc động mạch phổi do u thì có thể xét can thiệp một thì cắt u và bóc nội mạc động mạch phổi (tắc mạn tĩnh) hoặc lấy phần u gây thuyên tắc (tắc cấp tính). Trong cả 3 trường hợp trên, chỉ thấy vùng khuyêt cản quang trong nhĩ phải, ranh giới rõ, không xâm lấn các tổ chức xung quanh, động mạch phổi không có bất thường. Theo chúng tôi đây là một thăm dò rất cần thiết khi chẩn đoán u nhầy nhĩ phải, đặc biệt là các u có diện bám rộng.

Trường hợp thứ 3 , kích thước khối rất lớn - lên tới 70x50mm, chia nhiều múi, đàn hồi, chiếm phần lớn diện tích nhĩ phải, gây giãn nhĩ phải và có các biểu hiện ứ trệ tuần hoàn về tim phải, tĩnh mạch chủ trên giãn. Một báo cáo tổng kết 19 năm điều trị u nhày nhĩ của $\mathrm{NiNa}$ JS năm 2012 - có 7 trường hợp u nhày nhĩ phải, kích thước trung bình của tác giả chỉ là $51 \mathrm{~mm}$, đây được biết đến như một báo cáo về u nhày nhĩ phải có kích thước lớn nhất trên thế giới [6].

Phẫu thuật là phương pháp chính điều trị $\mathrm{u}$ nhầy nhĩ. Những khối u kích thước nhỏ, cuống rõ, ranh giới gọn có thể cắt bỏ qua mổ tim ít xâm lấm, thậm chí có thể không cần liệt tim như trường hợp thứ 2 . Những trường hợ $\mathrm{u}$ kích thước lớn, xâm lấn, tổn thương phức tạp, khó kiểm soát, được khuyến cáo nên mổ mở kinh điển để kiểm soát và xử lý tối đa các tổn thương, hạn chế những rối loạn về dẫn truyền và ảnh hưởng tới cấu trúc của van [7-12]. Nhiều tác giả cũng khuyên nên chủ động kẹp động mạch phổi trước để phòng tổ chức $\mathrm{u}$ vỡ trong khi thao tác phẫu thuật có thể gây tắc động mạch phổi [6-13]. Ca bệnh nhân thứ nhất trong báo cáo, trên siêu âm thấy khối u bám thấp sát chân tĩnh mạch chủ dưới, vì vậy chúng tôi chọn đặt canuyn tĩnh mạch chủ dưới qua tĩnh mạch đùi, chứ không đặt trục tiếp qua nhĩ phải, nhằm tránh làm vỡ $\mathrm{u}$. Chiều dài phần canuyn tĩnh mạch đùi được đo trước, làm sao không đưa 
đầu canuyn vào nhĩ phải, đồng thời không đặt dây thắt tĩnh mạch chủ dưới mà kẹp bằng cặp mạch máu lớn (clamp).

Ca bệnh nhân thứ 3 trong báo cáo là trường hợp khối u lớn, bám rộng vào vách liên nhĩ, nhiều múi - do đó được lựa chọn phẫu thuật mở kinh điển. Sau khi cắt hết toàn bộ $\mathrm{u}$, đã để lại lỗ thông liên nhĩ lớn -phải vá bằng miếng vá nhân tạo. Các tác giả cũng khuyến cáo cắt triệt để khối $u$ để hạn chế khả năng tái phát. Tỷ lệ tái phát theo A.Diaz khoảng 1-14\% [2]. Bệnh nhân này sau mổ diễn biến tốt, không có rối loạn nhịp. Nhìn chung, phẫu thuật tim hở cắt u nhầy nhĩ phải tương đối nhẹ nhàng, ít biến chứng, hậu phẫu thuận lợi và thường ra viện sớm sau mổ.

\section{KẾT LUẬN}

U nhầy nhĩ phải là bệnh lý hiếm gặp, chiếm $<20 \%$ u nhầy tim và khoảng $0,5 \%$ số phẫu thuật điều trị bệnh tim mắc phải ở người lớn tại bệnh viện Hữu nghị Việt Đức. Việc chẩn đoán còn khá muộn do bệnh ít dấu hiệu lâm sàng, nhưng không quá khó với các phương tiện hiện có. Mổ cắt $\mathrm{u}$ bằng phẫu thuật tim hở là giải pháp điều trị rất hiệu quả.

\section{TÀI LIẸU THAM KHẢO}

1. J. P. R. Soma Guhathakurta (2000). Surgical Treatment of Right Atrial Myxoma. Texas Heart Institute Journal, 27, 61-63.

2. D. S. C. Diaz A, Lawrence D, Hayward $M$ (2011). Left atrial and right ventricular myxoma: an uncommon presentation of a rare tumour. . Interact Cardiovasc Thorac Surg, 12, 622-623.

3. M. S (1959). Right atrium mixoma. circulation, 19, 910-917.

4. M. V. Arruda, D. M. Braile, M. R. Joaquim và cộng sự (2008). Resection of left ventricular myxoma after embolic stroke. Rev Bras Cir Cardiovasc, 23 (4), 578-580.
5. P. Vale Mde, A. Freire Sobrinho, M. V. Sales và cộng sự (2008). Giant myxoma in the left atrium: case report. Rev Bras Cir Cardiovasc, 23 (2), 276-278.

6. V. J. S. Nina, N. A. C. Silva, S. F. D. Gaspar và cộng sự (2012). Atypical size and location of a right atrial myxoma: a case report. Journal of Medical Case Reports, 6, 26-26.

7. L. Pinede, P. Duhaut và R. Loire (2001). Clinical presentation of left atrial cardiac myxoma. A series of 112 consecutive cases. Medicine (Baltimore), 80 (3), 159-172.

8. U. A. Croti, D. M. Braile, A. S. Souza và cộng sự (2008). [Right ventricle and tricuspid valve myxoma]. Rev Bras Cir Cardiovasc, 23 (1), 142-144.

9. O. Azevedo, J. Almeida, T. Nolasco và cộng sự (2010). Massive right atrial myxoma presenting as syncope and exertional dyspnea: case report. Cardiovasc Ultrasound, 8, 23.

10. M. Yuce, S. Dagdelen, M. Ergelen và cộng sự (2007). A huge obstructive myxoma located in the right heart without causing any symptom. Int J Cardiol, 114 (3), 405-406.

11. R. Oliveira, L. Branco, A. Galrinho và cộng sự (2010). Cardiac myxoma: a 13-year experience in echocardiographic diagnosis. Rev Port Cardiol, 29 (7-8), 1087-1100.

12. G. Samanidis, K. Perreas, P. Kalogris và cộng sự (2011). Surgical treatment of primary intracardiac myxoma: 19 years of experience. Interact Cardiovasc Thorac Surg, 13 (6), 597-600.

13. J. Jung, Y. S. Hong, C. J. Lee và cộng sự (2013). Successful Surgical Treatment of a Right Atrial Myxoma Complicated by Pulmonary Embolism. The Korean Journal of Thoracic and Cardiovascular Surgery, 46 (1), 63-67. 